\title{
Thin Layer Chromatography and Fluorescent Scanning Analysis of Porphyrins
}

\author{
Takashi Miura and Wakio Torinuki \\ Department of Dermatology, Tohoku University School of \\ Medicine, Sendai
}

\begin{abstract}
Midra, T. and ToRnnuki, W. Thin Layer Chromatography and Fluorescent Scanning Analysis of Porphyrins. Tohoku J. exp. Med., 1976, 121 (1), 57-61 - A combined technique of two dimensional thin layer chromatography with fluorescent scanning was applied to the estimation of urinary porphyrins in $\mathbf{2}$ patients with porphyria cutanea tarda. Porphyrin patterns were also examined with the technique on urine, liver and skin samples obtained from a hexachlorobenzene-induced porphyric rat. Results obtained showed that uroporphyrin and hepta-carboxylic porphyrin were predominant in the urine, liver and skin.

prophyria cutanea tarda; protoporphyrin; coproporphyrin; uroporphyrin; tri-, penta-, hexa-, hepta-carboxylic porphyrin
\end{abstract}

Porphyria cutanea tarda (PCT) is a most common disease for porphyria which usually develops during adult life showing skin photosensitivity on the exposed areas and is characterized by excess excretion of uroporphyrin (uro) in the urine. Recently biochemical analysis of porphyrins has shown that uro and heptacarboxylin porphyrin (hepta) were estimated in large quantities in the urine (Chu and Chu 1967; Dowdle et al. 1970; Piñol-Aguadé et al. 1975). In the present paper, we report results of biochemical analysis of urinary porphyrins in two patients with porphyria cutanea tarda using two dimensional thin layer chromatography (TLC) and the fluorescent scanning technique. Porphyrin patterns were also examined with this technique on the urine, liver and skin samples obtained from a hexachlorobenzene (HCB)-induced porphyric rat.

\section{Materials and Methods}

Cases subjected for analysis of urinary porphyrins

Case 1. A 49-year-old man who is a potator and used to drink 0.9 liter of Japanese Sake every night and/or a bottle of whisky $(760 \mathrm{ml})$ a week for the past 30 years. About 4 years ago, he noted an onset of several blisters on the face and dorsa of hands when exposed to the sun. Physical examination revealed brown pigmentation and finger-tip-sized scars on the face and dorsa of hands. On some areas, a few finger-tip-sized bullae were noted. Laboratory examination revealed accelerated $\operatorname{ESR}(122 \mathrm{~mm} / 1 \mathrm{hr}, 168 \mathrm{~mm} / 2 \mathrm{hr})$, anemia (RBC $393 \times 10^{4}, \mathrm{Hb} 13.4 \mathrm{~g} / 100 \mathrm{ml}$ ), slightly increased serum TTT $(5.4$ units), ZTT (14.9 units), fasting blood glucose $(104.3 \mathrm{mg} / 100 \mathrm{ml})$, increased $\beta$-globulin in the serum $(26.2 \%)$, normal serum iron value and normal total iron-binding capacity, and suspected initial changes

Received for publication, August 21, 1976. 
of liver cirrhosis on liver scintigram. Urine had a reddish color-tone, and quantitative estimation of urinary coproporphyrin (copro) and uro showed $3.8 \mathrm{mg} / \mathrm{day}$ and $12.7 \mathrm{mg} / \mathrm{day}$, respectively (Rimington 1971). Biopsy of a blister showed subepidermal bulla formation with intracellular edema of the epidermis and perivascular cell infiltration of the upper dermis.

Case 2. A 33-year-old man who is a potator and used to drink 0.5 liter of Japanese Sake every night for the past 10 years. About 5 years ago, he noted an onset of several blisters on exposed areas when exposed to the sun. Physical examination revealed brown pigmentation and several scars on the face, dorsa of hands, and $V$ neck. On some areas, several rice-grain-sized blisters and crusts were observed. Laboratory examination revealed accelerated $\operatorname{ESR}(26 \mathrm{~mm} / 1 \mathrm{hr}, 56 \mathrm{~mm} / 2 \mathrm{hr})$, slightly elevated serum GOT (56 Karmen units), increased serum $\beta$.globulin $(20.9 \%)$, normal serum iron value and normal total iron-binding capacity. Urine had a wine-like reddish color, and urinary copro and uro were estimated to be $1.3 \mathrm{mg} /$ day and $1.8 \mathrm{mg} /$ day by Rimington's method (1971), respectively. Biopsy of a blister showed a similar change to that in Case 1.

Analysis of whinary porphyrins with TLC.

Separation and quantitative estimation of urinary porphyrins were carried out on a TLC plate through the following 3 steps; 1) extraction and esterification of porphyrins, 2) two dimensional development on a TLC plate, and 3) fluorescent scanning.

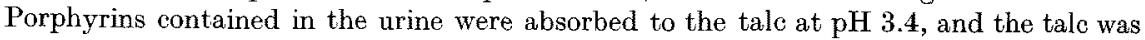
mixed with $5 \%$ methanol-sulphuric acid $(\mathrm{v} / \mathrm{v})$ and left for esterification for $24 \mathrm{hr}$ at room temperature in the dark. The methyl esters of porphyrins were extracted with chloroform, washed with saturated sodium acetate and $2 \%$ ammonia, and dried with an evaporator in the dark. The dried esters were resolved with a small amount of chloroform, and an aliquot of the esters in chloroform was spotted on a Merck silica gel 60 coated plate $(20 \times 20 \mathrm{~cm}$, gel layer $0.25 \mathrm{~mm}$ thick). The plate was developed first in a tank containing $80 \mathrm{ml}$ of toluene, $15 \mathrm{ml}$ of ethyl acetate and $3 \mathrm{ml}$ of ethanol (system A) for $30-40 \mathrm{~min}$ at room temperature in the dark, and the plate was dried up. The second development was done in another tank containing $60 \mathrm{ml}$ of chloroform, $20 \mathrm{ml}$ of white kerosene and $4 \mathrm{ml}$ of ethanol (system B) at $90^{\circ}$ to the axis of the first run for $30-40 \mathrm{~min}$ at room temperature in the dark (Smith 1975). Rf values of porphyrins with 4 to 8 carboxyl groups differed slightly from one another (Table 1) showing a good separation of copro, penta-carboxylic porphyrin (penta), hexa-carboxylic porphyrin (hexa), hepta and uro (Fig. 1). Porphyrm

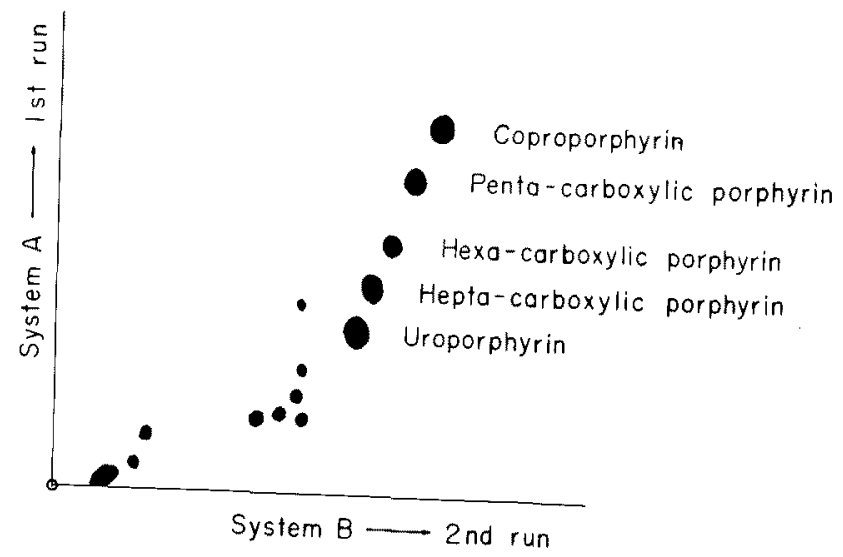

Fig. 1. Two dimensional separation of porphyrin esters with TLC from the urine extract from Case 1. 
TABLE 1. Rf values recorded using systems $A$ and $B$

\begin{tabular}{lcc} 
Porphyrin methyl ester & $\begin{array}{c}\text { System A } \\
(113 \mathrm{~mm} \text { run })\end{array}$ & $\begin{array}{c}\text { System B } \\
\text { (104 mm run) }\end{array}$ \\
\hline Coproporphyrin & 0.54 & 0.63 \\
Penta-carboxylic porphyrin & 0.46 & 0.60 \\
Hexa-carboxylic porphyrin & 0.38 & 0.56 \\
Hepta-carboxylic porphyrin & 0.31 & 0.54 \\
Uroporphyrin & 0.25 & 0.51 \\
\hline
\end{tabular}

System A contains $80 \mathrm{ml}$ of toluene, $15 \mathrm{ml}$ of ethyl acetate and $3 \mathrm{ml}$ of ethanol, and system B $60 \mathrm{ml}$ of chloroform, $20 \mathrm{ml}$ of white kerosene and 4 ml of ethanol.

contents of separated individual spots were estimated on the plate with a scanning fluorometer (SFR-21, Yamato Kagaku, Tokyo). About $600 \mathrm{~nm}$ wavelength rays were projected to a spot on the plate, and red fluorescence illuminated was scanned by the machine which gave various quantitative curves on a chart according to the intensity of the fluorescence registered. Scanning of known amounts of standard copro and uro (Sigma) gave a calibration curve on double logarithmic graph paper (Miura et al. 1975), and with this calibration curve, the porphyrin contents of subjected samples could be calculated.

Analysis of liver and skin porphyrins with TLC from a porphyric rat

Experiments were carried out on a porphyric rat produced after 2 months on HCB-diet $(0.25 \% \mathrm{w} / \mathrm{w})$, of which urinary copro and uro were $0.1 \mathrm{mg} / \mathrm{day}$ and $0.2 \mathrm{mg} / \mathrm{day}$ by Rimington's method (1971), respectively. Liver and skin porphyrins were extracted from autopsy or biopsy samples obtained from the rat and analyzed by the technique as reported previously (Miura et al. 1975); liver and skin uro were $84 \mu \mathrm{g} / \mathrm{g}$ wet weight and $0.3 \mu \mathrm{g} / \mathrm{g}$ wet weight, respectively.

\section{Results}

Two dimensional development on TLC gave a good separation of porphyrins with 4 to 8 carboxyl groups as shown in Fig. 1. The Soret maximum was $400 \mathrm{~nm}$ in copro, $403 \mathrm{~nm}$ in penta, $403 \mathrm{~nm}$ in hexa, $404 \mathrm{~nm}$ in hepta and $405 \mathrm{~nm}$ in uro.

Results of TLC analysis are summarized in Table 2. In PCT, uro and hepta predominated in urine; $68 \%$ in Case 1 and $45 \%$ in Case 2. In Case 2, isocoproporphyrin was detected in $7 \%$ of the total, Rf values of which were between those of copro and penta. In the porphyric rat, the urinary excretion pattern was similar to that in the PCT cases; proportions of individual porphyrins were roughly equal to those observed in Case 1 of PCT. A similar observation was obtained in liver porphyrins from the porphyric rat; a summed percentage of uro and hepta was $87 \%$ of the total. In the skin, uro and hepta predominated likewise in the urine and liver, and tri-carboxylic porphyrin (tri) and protoporphyrin (proto) were detected in $4 \%$ and $13 \%$ of the total, respectively. Rf values of tri and proto were 0.59 and 0.68 , respectively, in system $A$, and 0.65 and 0.70 in system $B$.

\section{Discussion}

Rf values of porphyrins with 2 to 8 carboxyl groups were close, ranging from 0.25 to 0.68 in system $A$ or from 0.51 to 0.70 in system $B$, and in order to separate 
TABLE 2. Relative proportions of porphyrins with 2 to 8 carboxyl groups isolated from patients with porphyria cutanea tarda and a hexachlorobenzeneinduced porphyric rats.

\begin{tabular}{|c|c|c|c|c|c|c|}
\hline & Uroporphyrin & $\begin{array}{l}\text { Hepta- } \\
\text { carbox }\end{array}$ & $\begin{array}{l}\text { Hexa- } \\
\text { ylic por }\end{array}$ & $\begin{array}{l}\text { Penta- } \\
\text { phyrin }\end{array}$ & Coproporphyrin & Others \\
\hline \multicolumn{7}{|l|}{ Urine } \\
\hline \multicolumn{7}{|l|}{ Porphyria cutanea } \\
\hline tarda case 1 & 44 & 24 & 10 & 9 & 13 & \\
\hline case 2 & 25 & 20 & 14 & 16 & 18 & $7^{*}$ \\
\hline Porphyric rat & 44 & 21 & 10 & 4 & 21 & \\
\hline \multicolumn{7}{|l|}{ Liver } \\
\hline Porphyric rat & 52 & 35 & 8 & 2 & 3 & \\
\hline \multicolumn{7}{|l|}{ Skin } \\
\hline Porphyric rat & 38 & 35 & 6 & 3 & 1 & $17 \dagger$ \\
\hline
\end{tabular}

Values were expressed as percentages of the total.

* Isocoproporphyrin. $\dagger$ Tri-carboxylic porphyrin (4\%) and protoporphyrin (13\%).

them clearly on a plate, two dimensional TLC was much more preferable than single one as shown in Fig. 1.

In two cases of PCT, the pattern of urinary porphyrin excretion was seen as uro $>$ hepta $>$ copro $>$ penta $>$ hexa, constituting approximately $35 \%, 22 \%, 16 \%$, $13 \%$ and $12 \%$ (mean values) of the total, respectively. In the literature, it has been reported that a characteristic pattern of urinary porphyrin excretion consists predominantly of uro and hepta $(58 \%$ and $23 \%$ by Chu and Chu $1967 ; 60 \%$ and 25 $\%$ by Dowdle et al. 1970; Piñol-Aguadé et al. 1975); our experimental data were in good agreement with those, though proportions of uro and hepta were lower than those afore-mentioned. In a HCB-induced porphyric rat, a similar pattern was observed in the urine consisting of uro $(44 \%)$ and hepta $(21 \%)$ predominantly. This suggests that a similar metabolic disturbance, as it is widely accepted, may be present in both conditions, PCT and HCB-induced porphyria. In the liver of porphyric rat, the pattern obtained was similar to that found in the urine; uro and hepta predominated $(52 \%$ and $35 \%$ ). Dowdle et al. (1970) reported that uro $(73 \%)$, hepta $(26 \%)$ and hexa $(1 \%)$ were the only porphyrins detected in the liver of one patient with the symptomatic porphyria. In the present paper, however, porphyrins with 5 and 4 carboxyl groups were also detected in the liver of HCBporphyria.

The skin porphyrin pattern is of interest. Skin porphyrin concentration is normally so low, except in some porphyria, that it has been difficult to estimate and differentiate individual porphyrins from the skin. In the previous paper, skin porphyrins were estimated by a technique combining single dimensional TLC with fluorescent scanning (Miura et al. 1975), and results obtained showed that uro and hepta were consistently detected in the porphyric rat skin. In the present paper, we employed two dimensional TLC reported by Smith (1975), and the analysis of skin porphyrin revealed that the pattern was uro $(38 \%)>$ hepta $(35 \%)>$ proto $(13 \%)>$ hexa $(6 \%)>\operatorname{tri}(4 \%)>$ penta $(3 \%)>$ copro $(1 \%)$. This closely resembled 
those obtained in the urine and/or in the liver except the presence of high concentration of proto and tri.

\section{Acknowledgment}

We are indebted to Dr. G. Fukushi, Aomori Prefectural Central Hospital, for his kind co-operation.

\section{References}

1) Chu, T.C. \& Chu, E.J.-H. (1967) Porphyrin patterns in different types of porphyria. Clin. Chem., 13, 371-387.

2) Dowdle, E., Goldswain, P., Spong, N. \& Eales, L. (1970) The pattern of porphyrin isomer accumulation and excretion in symptomatic porphyria. Clin. Sci., 39, 147-158.

3) Miura, T., Magnus, I.A., Jones, K. \& Doyle, M. (1975) Skin porphyrin and photosensitivity in the porphyric rat. Dermatologica, 151, 80-88.

4) Piñol-Aguadé, J., Herrero C., Almeida, J., Smith, S.G. \& Belcher, R.V. (1975) Thin layer chromatography and counter-eurrent analysis in porphyrias. Brit. J. Derm., 93, 277-289.

5) Rimington, C. (1971) Quantitative determination of porphobilinogen and porphyrins in urine and porphyrins in faeces and erythrocytes. Ass. clin. Path., Broadsheet 70 (Revised Broadsheet 36), August.

6) Smith, S.G. (1975) The use of thin layer chromatography in the separation of free porphyrins and porphyrin methyl esters. Brit. J. Derm., 93, 291-295. 